\title{
Definições de termos técnico-científicos do domínio da Linguística em dicionários gerais
}

PALAVRAS-CHAVE:

Termos técnico-científicos • Dicionários Gerais • Lexicografia

Beatrice Nascimento Monteiro

Ismael Paulo Cardoso Alves
RESUMO: A Lexicografia é uma área que tem se expandido de maneira intensa nos últimos anos. Inserido nesse viés de análise de obras lexicográficas, o presente artigo volta-se para um subconjunto doléxicogeral: os itens terminológicos, mais especificamente, termos do domínio da Linguística. Tomando, como corpus, dicionários gerais, objetivamos examinar as definições de termos técnico-científicos nessas obras, analisando a sistematicidade da inclusão de tais termos bem como a adequação e os detalhamentos dos textos definitórios. A discussão teórica apresentada é fundamentada principalmente em Biderman (2001), Krieger (2006, 2011), Almeida (2011), Maciel (2011), entre outros. Os dicionários gerais analisados foram: Houaiss e Aurélio (versões eletrônicas) e Aulete (digital). Selecionamos, para a análise, cinco itens lexicais que comportam tanto acepções mais gerais quanto específicas do domínio da Linguística. Os itens selecionados foram: língua, fala, texto, discurso e gênero. Como resultado, constatamos que os dicionários, muitas vezes, desconsideraram a polissemia dos itens lexicais, abarcando tão somente as acepções de uso corriqueiro das palavras, sem fazer menção a seu uso específico na área da Linguística. 


\section{1 . INTRODUÇÃO}

A lexicografia é uma área que tem se expandido de maneira intensa nos últimos anos. No Brasil, tal expansão manifestou-se, inclusive, em políticas educacionais concretas, como atesta o desenvolvimento de um PNLD (Plano Nacional do Livro Didático) voltado especificamente para avaliação de dicionários escolares desde 2006. Pode-se dizer também que, com essa expansão, oportunizou-se um diálogo entre teoria e prática lexicográfica.

Muito além da crítica em si mesma, os muitos trabalhos de análise de obra lexicográfica que têm surgido nos últimos anos visam ao desenvolvimento de uma melhor prática lexicográfica que possa atender efetivamente aos interesses da clientela dessas obras. Inserido nesse viés de análise de obras lexicográficas (também chamado de metalexicografia), o presente artigo volta-se para um produtivo subconjunto do léxico geral: os itens terminológicos, especificamente, termos do domínio da Linguística.

Tomando, como corpus, dicionários gerais, pretende-se, no decorrer deste artigo, examinar as definições de termos técnico-científicos nesses dicionários, analisando a sistematicidade da inclusão de tais termos, bem como a adequação e os detalhamentos dos textos definitórios.

\section{DICIONÁRIO GERAIS E TERMINOLÓGICOS: ASPECTOS COMUNS E ESPECIFICIDADES}

Embora o senso-comum tenda a encarar os dicionários como objetos homogêneos, sem diferenças entre si, há uma grande variedade de tipos de obras dicionarísticas, que possuem finalidades e público-alvo específicos. Existem, para citar apenas alguns tipos, dicionários escolares, que visam primordialmente à prática pedagógica, dicionários etimológicos, que procuram dar conta da origem e da evolução semântica de diversas palavras, dicionários bilíngues, geralmente utilizados como instrumentos para tradução de textos; entre vários outros.

Cada um deles é objeto de uma ciência do léxico específica. Os dicionários gerais são objetos da Lexicografia, enquanto os terminológicos são enfocados pela Terminologia. Entretanto, como ressalta Krieger (2011), a separação entre Lexicografia e Terminologia não é rígida, uma vez que não há demarcação clara entre léxico geral e léxico especializado:

A indistinção no léxico deve-se, sobretudo, ao fato de que palavras e termos não se distinguem a priori, mas instituem-se de uma ou outra forma de acordo com o conteúdo semântico que veiculam. Um item lexical será palavra quando seu significado não é específico de um conhecimento especializado, será termo quando é usado num universo comunicacional profissional, expressando um conceito próprio da temática em pauta. (KRIEGER, 2011, p. 75) [grifos da autora]. 
Andrade (2001) considera que um critério diferenciador entre palavra e termo é o caráter monossêmico desse em contraposição àquele. Diz a autora:

[...] ao contrário da palavra, que é fundamentalmente polissêmica, o termo tende à monossemia, pois, mesmo quando participa da terminologia de várias áreas (no caso de variável), no trabalho terminológico, considera-se apenas a significação referente ao tema escolhido. (ANDRADE, 2001, p. 198).

Contudo, tal critério não se aplica à generalidade dos termos técnicocientíficos, uma vez que vários deles apresentam realização polissêmica, ainda que em um mesmo domínio. Os próprios termos que serão analisados no decorrer do artigo são exemplos desse fato. Assim, concorda-se com a afirmação supracitada de Krieger (2011) de que a delimitação entre palavra e termo não se institui a priori, mas é estabelecida conforme o uso.

Assim, muitas vezes, o mesmo item lexical realiza-se tanto como palavra, ou seja, sem estar associado conceitualmente a um domínio específico do conhecimento, quanto como termo, isto é, como lexia própria de um dado campo científico, artístico, técnico. Esses tipos de itens lexicais, que comportam sentidos gerais e especializados, que são o foco de análise deste artigo.

Os dicionários gerais caracterizam-se por tentar repertoriar exaustivamente o léxico utilizado por uma sociedade. Tal empreendimento é sempre uma tentativa, pois "nenhum dicionário, por mais volumoso que seja, dará conta integral do léxico de uma língua de civilização" (BIDERMAN, 2001, p. 130). Uma vez que pretendem apresentar um inventário exaustivo do repertório lexical de uma sociedade, tais dicionários trazem, em seu escopo, vocábulos variados que incluem tanto arcaísmos quanto neologismos; assim como regionalismos e empréstimos advindos de outros idiomas.

Almeida (2011) ressalta que, uma vez que os dicionários gerais são objetos que refletem a cultura de uma sociedade, a presença de termos que expressam conceitos importantes nas ciências, artes e técnicas, aspectos dessa cultura, é imprescindível. Contudo, embora se espere que estejam incluídos na nomenclatura de dicionários gerais, os termos técnicocientíficos constituem o foco de outro tipo de dicionário: os dicionários terminológicos ou especializados.

Tais dicionários buscam apresentar um inventário de termos conceitualmente relevantes e produtivos em dado domínio do saber. Assim, existem dicionários dos domínios de Medicina, Filosofia, Artes, Direito, Linguística, que abordam termos específicos dessas áreas, os quais, muitas vezes, são itens lexicais de uso mais geral que adquirem, dentro do respectivo domínio, acepções específicas.

Quando se trata das diferenças entre dicionários gerais e terminológicos, um dos aspectos que precisa ser levado em conta é o público-alvo. Enquanto 
os dicionários gerais voltam-se para os falantes de uma língua de maneira geral, os dicionários terminológicos visam a um público bastante específico: aqueles que estão interessados em conhecer a terminologia do campo abordado. Segundo Barros (2011, p. 148), "normalmente, os dicionários de área de especialidade são de grande utilidade para iniciantes na matéria, que ainda não dominam a terminologia própria da área”. Portanto, esses dicionários podem funcionar como forma de acesso ao conhecimento construído e acumulado em dado domínio técnico, artístico ou científico.

A diferença de público-alvo dos dois dicionários influencia na microestrutura dos mesmos, ou seja, na constituição dos verbetes. Enquanto em dicionários gerais, a microestrutura comporta um conjunto de acepções correntes da palavra, assim como uma série de informações de natureza metalinguística (classe gramatical, gênero, pronúncia, etimologia etc); em dicionários especializados, o enfoque é no desenvolvimento de um conceito, relativo às acepções que o termo possui no domínio em questão, raramente aparecendo informações metalinguísticas. Segundo Maciel (2011), esse tipo de informação só costuma aparecer quando a obra é voltada para tradutores e redatores.

Barros (2011) ressalta que se costumava diferenciar o fazer lexicográfico do terminográfico levando-se em consideração o direcionamento utilizado na seleção dos verbetes. De fato, Krieger (2006) apoia-se nessa distinção quando afirma:

[...] a lexicografia assume caráter semasiológico, porquanto se orienta do significante para o significado; em sentido inverso, a terminografia, ou seja, a área de produção de obras terminológicas, fundamenta-se na onomasiologia, selecionando os itens lexicais especializados a partir dos conhecimentos que veiculam. (KRIEGER, 2006, p. 144).

Contudo, hoje, essa perspectiva modificou-se e "o trabalho de ambas as áreas dicionarísticas é visto como onomasiológico em alguns aspectos e semasiológicos em outros” (BARROS, 2011, p. 145). Essa visão é também partilhada por Maciel (2011), a qual afirma que "os dois caminhos não são exclusivos, são trilhadas em ambas [obras lexicográficas e terminográficas], ora em direção ao conceito, ora em busca da palavra que o possa denominar" (p. 147). Um argumento em favor dessa visão é que obras de caráter terminológico também podem valer-se do critério da frequência de uso para a composição da sua nomenclatura, isto é, para a escolha do conjunto de verbetes que constituirão o dicionário. De forma análoga, o dicionário geral também pode utilizar-se de critérios onomasiológicos, de modo a não deixar de contemplar, por exemplo, acepções importantes de uma dada palavra, ainda que essas não apareçam nos corpora utilizados.

O tópico seguinte trata especificamente da questão da inclusão de termos técnico-científicos em dicionários gerais, uma vez que, embora esses não sejam elaborados especificamente para repertoriar o vocabulário terminológico, espera-se que sua nomenclatura abranja esse subconjunto do léxico geral. 


\section{A INCLUSÃO DE TERMOS TÉCNICO-CIENTÍFICOS EM DICIONÁRIOS GERAIS}

Se está claro que a nomenclatura de dicionários gerais deve contemplar também os termos técnico-científicos, uma vez que esses integram aspectos importantes da cultura geral de um povo, a questão de como $e$ em que extensão integrar esse subconjunto do léxico em dicionários gerais ainda parece estar em aberto.

Como aponta Krieger (2011, p. 76), "praticamente inexiste literatura sobre o registro de termos técnicos em dicionários de língua”. Uma consequência disso é que a inclusão de termos em dicionários parece ser ainda assistemática, como mostra o trabalho da citada autora, que analisa minidicionários.

Almeida (2011), por sua vez, sugere alguns critérios para inserção de termos técnicos em obras lexicográficas. Primeiramente, ele considera que se deve montar um corpus que abranja as seguintes categorias de texto: científicos de divulgação, publicados em periódicos voltados para público não-especializado; informativos, publicados em jornais e revista; instrucionais, presentes em manuais e materiais didáticos e textos publicitários, como campanhas governamentais de saúde, por exemplo.

Para ele, a montagem do corpus é uma etapa de suma importância que norteará toda a seleção de verbetes terminológicos. Uma vez selecionado o corpus, o lexicógrafo propõe que se utilizem os seguintes critérios para a inclusão de termos técnico-científicos: frequência de uso; relevância semântica no domínio de conhecimento em apreço, já que termos de grande importância em uma área podem não aparecer no corpus; pertinência do domínio em questão para a atualidade, pois alguns campos, segundo Almeida (2011), têm ganhado destaque na atualidade,como informática, biotecnologia, saúde pública, entre outros.

É difícil saber se os dicionaristas estão atendendo a esses critérios sugeridos pelo lexicógrafo, uma vez que, como mostra Krieger (2011), muitos dicionários não explicitam qual tratamento é dado aos termos técnicos em sua proposta lexicográfica. Os dicionários analisados pela autora também não especificam quais domínios do conhecimento têm sua terminologia contemplada no corpo do dicionário, só sendo possível informar-se sobre isso lendo a lista de abreviaturas da obra, que, em geral, apresenta dados de natureza bastante variada, incluindo marcas de uso de diversos tipos.

Essa frequente ausência de informação na proposta lexicográfica dificulta a consulta do leitor aos termos técnicos em dicionários gerais, pois ele não é provido pela obra de uma orientação inicial sobre como encontrá-los, nem recebe informação sobre qual o critério de inserção de terminologia na obra. Constata-se, então, que a inclusão de termos técnico-científicos em dicionários gerais ainda é uma questão que precisa ser discutida e analisada. 


\section{METODOLOGIA}

Neste trabalho, realizamos uma análise qualitativa das definições de termos técnico-científicos constante em 3 (três) dicionários gerais, Houaisse Aurélio (versões eletrônicas) e Aulete (versão digital, acessado online). Selecionou-se, para a análise, 5 (cinco) itens lexicais: língua, fala, texto, discurso e gênero. $\mathrm{O}$ motivo da escolha desses termos é que eles possuem tanto acepções de uso corriqueiro, sem pertencimento a um domínio técnico-científico, o que justifica sua inclusão em dicionários gerais, quanto acepções relevantes na terminologia dos estudos da linguagem, isto é, são também termos da Linguística.

As definições de dicionários gerais foram transcritas integralmente, retirando-se apenas as informações linguísticas (etimologia, classe gramatical, gênero gramatical etc.) e as expressões idiomáticas, exceto quando essas se mostraram relevantes para a análise, a qual será apresentada no decorrer do próximo tópico.

\section{ANÁLISE DAS DEFINIÇÕES DOS TERMOS SELECIONADOS}

Selecionamos, para esse trabalho, itens lexicais com realização polissêmica, os quais comportam-se tanto como palavras, ou seja, são utilizados sem estarem associados conceitualmente a um domínio específico do conhecimento, quanto como termos, isto é, como itens dotados de um determinado sentido em um dado campo técnico-científico. Em nossa análise, procuramos identificar se esses dois aspectos são contemplados pelos dicionários gerais, analisando se há sistematicidade e adequação na inclusão de tais termos nesse tipo de obra lexicográfica.

\subsection{DEFINIÇÕES DO TERMO LÍNGUA}

Em dicionários gerais, espera-se que as definições reportem-se tanto às acepções gerais de língua, enquanto palavra de uso geral, quanto às acepções especializadas que caracterizam a língua, enquanto termo específico da Linguística. O dicionário Houaiss apresenta as seguintes acepções para esse item lexical ${ }^{1}$ :

1 Rubrica: anatomia geral.

órgão muscular recoberto de mucosa, situado na boca e na faringe, responsável pelo paladar e auxiliar na mastigação e na deglutição, e tb. na produção de sons

1. Optou-se por uma questão de espaço e de correlação com o tema discutido apresentar apenas as acepções de língua enquanto substantivo feminino, excluindo-se as acepções de língua como substantivo masculino apresentadas pelos dicionários em análise. 
2 Rubrica: anatomia zoológica.

estrutura homóloga encontrada em certos invertebrados, como moluscos

3 Rubrica: anatomia zoológica.

m.q. hipofaringe ("estrutura mediana")

4 Derivação: por analogia.

qualquer coisa que tenha o aspecto de língua

Ex.: l. de fogo

5 Rubrica: linguística.

sistema de representação constituído por palavras e por regras que as combinam em frases que os indivíduos de uma comunidade linguística usam como principal meio de comunicação e de expressão, falado ou escrito

5.1 Uso: sentido absoluto.

o idioma nacional

6 Rubrica: linguística.

para o linguista Ferdinand de Saussure (1857-1913), o sistema abstrato de signos interrelacionados, de natureza social e psíquica, obrigatório para todos os membros de uma comunidade linguística

$7 \quad$ Rubrica: estilística, linguística.

estilo de expressão particular a um grupo social, profissional, cultural, a um escritor, um movimento, uma escola, uma época etc.; linguagem

Exs.: a l. dos matemáticos

a l. de Guimarães Rosa

8 Derivação: sentido figurado.

maneira cruel, maldizente de referir-se aos outros, própria ger. de pessoas falastronas

Ex.: que l. tem essa criatura!

No dicionário Houaiss, são abordadas tanto acepções mais gerais do item lexical língua, quanto acepções específicas do domínio da Linguística (acepções 5, 6 e 7). A acepção 5 (cinco) faz referência à concepção de língua como sistema de representação e meio de comunicação correlacionado a dada comunidade linguística. A acepção 6 (seis) é a definição dada por Saussure: a língua como sistema de signos, caracterizada como abstrata, social e psíquica. A acepção 7 (sete), por sua vez, traz uma noção de língua equiparada à concepção de estilo. Existe, portanto, uma abordagem de acepções relevantes de língua no domínio da Linguística.

Já o dicionário Aulete aborda as seguintes acepções:

1. Anat. Órgão muscular móvel, situado na boca, que serve para sentir os sabores, deglutir e articular sons

2. Qualquer coisa cuja forma lembra a desse órgão: “...Apareceramlhes, então, línguas como de fogo..." ("Atos dos apóstolos” in $A$ Bíblia de Jerusalém)

3. Ling. Sistema de comunicação e expressão verbal de um povo, nação, país, etc., que permite aos usuários expressar pensamentos, desejos e emoções; IDIOMA

4. O idioma vernáculo 
5. Maneira de falar ou escrever característica de um autor, movimento ou época; LINGUAGEM: a língua dos romancistas.

6. Maneira de se referir a outras pessoas: Tinha uma língua ferina.

Entre as acepções abordadas, apenas uma traz a rubrica Ling., referente à Linguística, a acepção 3 (três), na qual língua é apontada como sinônimo de idioma. O dicionário não apresenta outras acepções desse item lexical na terminologia da linguística. Além disso, por ser posta como sinônima de idioma, tal acepção parece ainda estar bastante próxima do sensocomum sobre o significado de língua.

No Aurélio, encontram-se as seguintes acepções:

1. Anat. Órgão muscular alongado, móvel, situado na cavidade oral, a cuja parede inferior está preso pela base, e que serve para a degustação, deglutição, e desempenha papel importante na articulação de sons.

2. Designação comum a diversos objetos que têm semelhança com esse órgão.

3. Língua esp. de boi ou de porco, para uso na alimentação humana.

4. O conjunto das palavras e expressões usadas por um povo, por uma nação, e o conjunto de regras da sua gramática; idioma.

5. A língua vernácula.

6. Modo de expressão escrita ou verbal de um autor, de uma escola, de uma época; estilo; linguagem: a língua de Graciliano Ramos.

7. Fig. A linguagem (5) própria de uma pessoa ou de um grupo: Naquela família não há conflito de gerações: pai e filho usam a mesma língua.

8. E. Ling. Sistema de signos [v. signo (4)] que permite a comunicação entre os indivíduos de uma comunidade linguística. [Sin., nesta acepç., discurso (4).]

9. E.Ling. Sistema linguístico que resulta da aquisição (4). [Cf, nesta acepç.gramática (6)]

10. E.Ling. Contínuo de variedades linguísticas que, por razões culturais, políticas, históricas, geográficas, é considerado como entidade única que delimita uma comunidade linguística (q.v)

11. Qualquer dos sons emitidos por um animal e que imitam a voz humana; fala: Sempre achava graça na língua do seu papagaio.

O dicionário aborda 3 (três) acepções do item lexical língua específicas do domínio da Linguística. A acepção 8 (oito) destaca a propriedade da língua de funcionar como meio de comunicação dentro de uma comunidade linguística. A acepção 9 (nove) parece estar ligada à teoria gerativa-transformacional por equiparar língua à gramática e também por ressaltar a questão da aquisição. Já a acepção 10 (dez), bastante adequada às discussões contemporâneas no domínio da Linguística, ressalta a questão da variação linguística. Percebe-se, portanto, que o Aurélio aborda 
adequadamente língua enquanto termo técnico-científico da Linguística, considerando, inclusive, a polissemia desse termo dentro da própria área. O próximo tópico trata da abordagem do termo fala nos dicionários gerais supracitados.

\subsection{DEFINIÇÕES DO TERMO FALA}

O dicionário Houaiss apresenta 11 (onze) acepções para o item lexical fala. São elas:

1 ato ou efeito de falar

1.1 faculdade que tem o homem de se expressar, de se comunicar por meio de palavras

1.2 o uso dessa faculdade

1.3 aquilo que se exprime por palavras; colóquio

Ex.: ontem tive uma f. com o seu pai

2 m.q. linguagem("maneira de exprimir-se")

3 m.q. linguajar (subst.)

4 m.q. falar ("variedade regional de língua”)

5 Rubrica: linguística.

para Ferdinand de Saussure (1857- 1913), parte da linguagem que se manifesta como ato individual, por oposição a língua[Certos linguistas substituem fala por discurso e referem-se à dicotomia língua/discurso.]; parole

6 palavra, dito, frase

Ex.: não esqueceu as antigas $f$. do namorado

$7 \quad$ alocução, discurso

Ex.: a f. do ministro

8 cada trecho que cabe a um ator ou um locutor num diálogo, monólogo ou narração

Ex.: decorou suaf.

9 tom de voz

Ex.: uma f. maviosa

10 Derivação: por extensão de sentido.

emissão de sons nos animais

Ex.: $a f$. das aves

11 Rubrica: termo jurídico.

em um processo, aquilo que uma das partes alega ou requer dentro dos autos

Entre as várias acepções do itemlexical fala, o Houaiss apresenta uma acepção especializada d o domínio da Linguística, a acepção 5 (cinco). Nesta, é apresentada a concepção de fala saussuriana, destacando a distinção língua/fala. Poderiam ter sido abordadas outras concepções de fala vigentes na Linguística, não apenas a concepção de Saussure e essa poderia ter sido definida com maior detalhes. Ainda assim, é importante ressaltar que o dicionário não desconsiderou a produtividade do item lexical fala como termo técnico-científico da ciência da linguagem. 
O dicionário Aulete apresenta as seguintes acepções:

1. Ação ou resultado de falar

2. Aptidão ou capacidade de se expressar verbalmente

3. Exposição oral: Sua fala foi muito convincente.

4. Maneira de pronunciar (problemas de fala); DICÇÃO

5. O que se exprime pela palavra: O professor teve uma fala séria com os estudantes.

6. Cada parte de um texto dita por um ator; apresentador ou locutor: Esqueceu sua fala na primeira cena.

7. Exposição oral dirigida ao público: A fala do homenageadoemocionou os presentes.

8. Timbre ou tom da voz (fala estridente)

9. O som produzido pelos animais: Um especialista distingue a fala dos diferentes pássaros.

10. Ling. Qualquer modo de falar us. por uma pessoa ou grupo ou em determinadas circunstâncias.

11. Ling. Uso da língua visto como interação de um sistema gramatical e fatores determinados por situações diversas

12. Ling. Conteúdo fônico de uma língua

13. Ling. Uso da língua

No dicionário Aulete, são apresentadas 4 (quatro) acepções do item lexical fala no domínio específico da Linguística. Na acepção 10 (dez), a fala é definida como um "modo de falar" específico de uma pessoa, grupo ou circunstância (noção que parece próxima do conceito de registro). $\mathrm{Na}$ acepção 11 (onze), a fala é definida como interação entre gramática e fatores situacionais. A acepção 12 (doze) diz respeito à concepção de fala como conteúdo fônico e a acepção 13 (treze), à concepção mais tradicional desse termo, como realização da língua. São abordadas, portanto, diversas concepções de fala no domínio da Linguística.

O Aurélio, por sua vez, apresenta as seguintes acepções para fala:

1. Ação ou faculdade de falar que se exprime por palavra: A fala é uma característica humana.

2. Aquilo que se exprime por palavras: Procurei-o, deu-me bons conselhos, e depois de sua fala pude enfrentar a situação.

3. P. Ext. Emissão de sons por animais: Divertia-se com a fala dos animais.

4. Palavra, dicção, vocábulo.

5. Alocução, discurso: A fala do presidente será às 10 horas.

6. Parte do diálogo dita por um dos interlocutores: É excelente a fala do segundo personagem da peça.

7. Timbre ou tom da voz.

8. E. Ling. V. variedade (6)

9. E.Ling. V. discurso (4)

10. E.Ling. V. discurso (5)

11. E.Ling. Substância fônica de uma língua 
O Aurélio apresenta, portanto, 4 (quatro) acepções para item lexical fala específicas do domínio da Linguística. Dessas, as 3 (três) primeiras desenvolvem-se pela apresentação de sinônimos, através de remissões. A acepção 11 (onze), por sua vez, descreve a fala como sendo a "substância fônica de uma língua", destacando sua realidade enquanto fenômeno físico. O próximo tópico aborda diferentes definições do termo texto.

\subsection{DEFINIÇÕES DO TERMO TEXTO}

O item lexical texto é bastante produtivo tanto como palavra quanto como termo. O dicionário Houaiss traz as seguintes acepções para esse item:

1 conjunto das palavras escritas, em livro, folheto, documento etc. (p.opos. a comentários, aditamentos, sumário etc.); redação original de qualquer obra escrita

Ex.: um t. manuscrito

2 trecho ou fragmento de obra de um autor

Ex.: o t. de Graciliano Ramos

3 passagem da Bíblia que se toma para servir de tema ou assunto de um sermão

4 qualquer material escrito que se destina a ser falado ou lido em voz alta

5 Rubrica: artes gráficas.

parte principal de livro ou outra publicação, com exclusão dos títulos, subtítulos, epígrafes, gravuras, notas etc.

Como se pode observar, inexiste, no dicionário Houaiss, a acepção de texto como termo técnico-científico da área da Linguística. A única rubrica que aparece é relativa às "artes gráficas", o que é problemático sendo texto uma noção tão importante para a ciência linguística. Mesmo que se considere que, para o Houaiss, a acepção de texto na área da Linguística pode ser equiparada com a noção corrente de texto (o que, por si só, seria questionável), ainda assim o dicionário teria incorrido em um equívoco, pois todas as acepções dadas referem-se, direta ou indiretamente, ao texto como restrito à modalidade escrita, concepção há muito tempo superada nos estudos linguísticos.

Além disso, a noção de texto dada pelo Houaiss não parece abranger as diversas realizações linguísticas cotidianas, faladas ou escritas, pois praticamente todas as acepções fazem referência ao texto enquanto parte de uma obra, o que exclui dessas definições textos de diversos gêneros do dia a dia. A acepção 4 (quatro), por sua vez, não se refere à relação com uma obra, mas afirma que o texto "se destina a ser falado ou lido em voz alta”, ou seja, faz referência a um texto de utilização bastante específica, que auxilia uma apresentação oral.

No Aulete, encontram-se as seguintes acepções para texto: 
1. Encadeamento de palavras ou frases escritas.

2. Qualquer obra escrita, tomada em sua versão original (texto bíblico, texto jurídico)

3. Restr. Passagem da Bíblia citada por orador sacro, para ser tema de sermão

4. Fragmento da obra de um autor: Usamos, no exercício, um texto de Plínio Marcos.

5. Matéria escrita ou impressa (em oposição a ilustração, iconografia)

6. Rád. Telv. Qualquer conjunto de palavras ou frases a ser lido em voz alta.

Assim como o Houaiss, o Aulete não traz, entre as acepções apresentadas, nenhuma referente ao domínio da Linguística. O dicionário só contempla as acepções mais correntes, que associam texto somente à modalidade escrita da língua, equívoco também cometido pelo Houaiss.

Já o dicionário Aurélio traz as seguintes acepções para a entrada texto:

1. Conjunto de palavras, frases escritas: o texto de um livro, de um estatuto, de uma inscrição.

2. Obra escrita considerada na sua redação original e autêntica (por oposição a sumário, tradução, notas, comentários, etc.): o texto da Bíblia, o texto da lei.

3. Restr. Palavras bíblicas que o orador sacro cita, fazendo-as tema de sermão.

4. Página ou fragmento de obra característica de um autor: um texto de Machado de Assis.

5. Texto (1) manuscrito ou impresso (por oposição a ilustração).

6. Qualquer texto (1) destinado a ser dito ou lido em voz alta: um texto teatral; o texto de um noticiário.

7. E. Ling. Excerto de língua escrita ou falada, de qualquer extensão, que constitui um todo unificado.

8. E.Ling. Toda e qualquer expressão, ou conjunto de expressões, que a escrita fixou.

Diferentemente dos demais dicionários, o Aurélio traz juntamente com as acepções mais gerais de texto, acepções específicas do domínio da Linguística, abreviada, nas rubricas, como E. Ling. (Estudos Linguísticos). A acepção 8 (oito) ainda vincula o texto somente à modalidade escrita, mas a acepção 7 (sete) refere-se tanto a performances linguísticas orais quanto escritas. Embora o dicionário não abranja a grande extensão de acepções que o termo texto possui na Linguística, pode-se ver um avanço em relação aos outros dicionários gerais analisados, uma vez que são contemplados sentidos terminológicos desse item lexical e não apenas as acepções mais gerais. 


\subsection{DEFINIÇÕES DO TERMO DISCURSO}

No dicionário Houaiss, o verbete de discurso inclui 3 (três) acepções com rubricas do domínio da Linguística, como se pode observar a seguir:

1 mensagem oral, ger. solene e prolongada, que um orador profere perante uma assistência

Ex.: d. de formatura

2 Rubrica: literatura.

peça de oratória ger. para ser proferida em público, ou escrita como se fosse para esse fim; sermão, oração

3 série de enunciados significativos que expressam a maneira de pensar e de agir e/ou as circunstâncias identificadas com um certo assunto, meio ou grupo

Ex.: d. psicanalítico

4 Rubrica: filosofia.

raciocínio que se realiza pela sequência que vai de uma formulação conceitual a outra, segundo um encadeamento lógico e ordenado

6 Rubrica: linguística.

a língua em ação, tal como é realizada pelo falante [Muitos linguistas substituem discurso por fala, na dicotomia língua/discurso.]

7 Rubrica: linguística.

segmento contínuo de fala maior do que uma sentença

8 Rubrica: linguística.

enunciado oral ou escrito que supõe, numa situação de comunicação, um locutor e um interlocutor

Percebe-se um tratamento do item lexical discurso bastante distinto do que foi dado a texto, o qual sequer foi apontado como termo técnico da Linguística. No verbete, são apresentadas diferentes definições de discurso dentro da terminologia específica da Linguística ao lado de acepções mais correntes como "mensagem oral, ger. solene e prolongada, que um orador profere perante uma assistência”, o que é esperado de um dicionário geral de língua. Além disso, o dicionário dá conta, inclusive, da polissemia relativa ao termo discurso dentro da própria terminologia linguística.

Já no dicionário Aulete encontram-se as seguintes acepções:

1. Exposição oral feita em público ou preparada para ser lida em público pelo próprio orador ou não: Preparou um $\underline{\text { discurso especial }}$ para a cerimônia.

2. Ação ou modo de expressar oralmente pensamentos, opiniões: Tinha um discurso convincente.

3. Conjunto de sentenças que constituem uma disciplina, teoria etc. (discurso psicanalítico)

4. Ling. Unidade maior que a frase; ENUNCIADO 
5. Ling. Qualquer instância autêntica de uso da língua em todas as suas manifestações, nas modalidades escrita ou falada, incluindo o contexto de sua produção

6. Ling. Qualquer enunciado, oral ou escrito, que estabelece uma comunicação entre seu emissor (locutor) e seu receptor (interlocutor)

O dicionário Aulete, assim como o Houaiss, traz tanto acepções mais gerais no verbete discurso quanto acepções específicas do domínio da Linguística. Asacepções específicas referem-se a discurso como sinônimo de enunciado; como instância de uso da língua; e como mecanismo através do qual se estabelece um ato comunicativo. Há, portanto, uma consideração da polissemia que esse termo apresenta nos estudos linguísticos.

O dicionário Aurélio, por sua vez, apresenta as seguintes acepções para discurso:

1. Peça oratória proferida em público ou escrita como se tivesse de o ser.

2. Exposição metódica sobre certo assunto; arrazoado.

3. Oração, fala.

4. E. Ling. Qualquer manifestação concreta da língua. [Sin., nesta acepç.: fala e (fr.) parole.]

5. E.Ling. Unidade linguística maior do que a frase; enunciado, fala.

6. Ant. Raciocínio, discernimento.

7. Fam. Palavreado vão, e/ou ostentoso: Nada de discurso, vá direto ao assunto.

8. Fam. Fala longa e fastidiosa, de natureza ger. moralizante: Toda vez que chega tarde, o pai faz-lhe um discurso.

9. Liter. Qualquer manifestação por meio da linguagem, em que há predomínio da função poética (q. v.): "O estatuto americano dos textos borgianos não invalida o fato de ele pertencer ao discurso do sistema cultural universal.” (BellaJozef. Jorge Luis Borges, p. 41).

No Aurélio, são apresentadas, juntamente com outras acepções mais gerais da palavra discurso e acepções específicas de outros domínios, dois sentidos, do termo, próprios dos Estudos Linguísticos: discurso como manifestação concreta da língua e como unidade linguística superior à frase. Contudo, pode-se dizer que, na abordagem do termo discurso como termo técnico da Linguística, os dicionários Aurélio e Aulete foram mais completos que o Houaiss, apresentando maior quantidade de acepções desse termo no domínio da Ciência da Linguagem. 


\subsection{DEFINIÇÕES DO TERMO GÊNERO}

Todos os dicionários gerais analisados são atuais, portanto, espera-se que eles abordem tanto a acepção de gênero gramatical/morfológico quanto de gênero de discurso, já consagrada nos estudos linguísticos contemporâneos. No Houaiss, são apresentadas as seguintes acepções para gênero:

1 conjunto de seres ou objetos que possuem a mesma origem ou que se acham ligados pela similitude de uma ou mais particularidades

2 Derivação: por extensão de sentido.

tipo, classe, espécie

Exs.: na festa havia todo o g. de gente

não usa esse g. de roupa

3 Rubrica: lógica.

qualquer classe de indivíduos com propriedades em comum, passível de subdivisão em classes mais restritas, as espécies

4 Rubrica: biologia.

categoria taxonômica que agrupa espécies relacionadas filogeneticamente, distinguíveis das outras por diferenças marcantes, e que é a principal subdivisão das famílias

5 Rubrica: artes plásticas.

cada uma das categorias em que são classificadas as obras artísticas, segundo o estilo e a técnica usada

Ex.: g. surrealista

6 Rubrica: literatura.

cada uma das divisões que englobam obras literárias de características similares [São primordialmente três: lírico, épico e dramático.]

7 Rubrica: geometria analítica.

diferença entre o número máximo de pontos duplos que uma curva unicursal pode ter e o número dos que ela realmente possui; deficiência 8 Rubrica: geometria analítica.

metade do número de cortes que devem ser feitos em uma superfície para que ela se torne simplesmente conexa

9 Rubrica: gramática, linguística.

categoria das línguas que distingue classes de palavras a partir de contrastes como masculino/feminino/neutro, animado/inanimado, contável/não contável etc.

Nesse dicionário, a acepção de gênero, enquanto termo técnico-científico da Linguística, somente refere-se ao gênero morfológico. $\mathrm{O}$ dicionário ainda remete aos gêneros literários, apontados por Aristóteles, mas não faz nenhuma referência aos gêneros de discurso, embora o dicionário de Ducrot\&Todorov, em 1972, já reconhecesse sua existência.

No Aulete, são apresentadas as seguintes acepções: 
1. Conceito classificatório que engloba todos os grupos com características básicas comuns em seus caracteres essenciais (espécies) num universo ou classe de seres ou coisas.

2. P. ext. Conjunto de seres ou coisas que têm a mesma origem ou que se encontram ligados pela semelhança de suas principais características: o gênero humano.

3. Espécie, tipo: Ele gosta de todo o gênero de pessoas.

4. Biol. Categoria taxonômica de animais ou vegetais que se situa abaixo de família e acima de espécie

5. Gram. Categoria gramatical que classifica nomes e pronomes de uma língua, distinguindo-os, p. ex., entre masculino, feminino e neutro

6. Liter. Categoria distintiva do tipo de composição literária: $O$ romance é um gênero literário, a poesia, outro.

7. Art.pl. Cin. Natureza do assunto tratado por um artista, ou tipo ou estilo específico de realização artística: filme do gênero romântico.

8. Antr. A forma que a diferença sexual assume, nas diversas sociedades e culturas, e que determina os papéis e o status atribuídos a homens e mulheres e a identidade sexual das pessoas.

9. Ret. Divisão dos discursos conforme os fins a que se propõem e os meios que empregam para tal.

10. Geom.An. Numa superfície, metade do número de cortes necessários para que se torne simplesmente conexa

11. Fil. Para Aristóteles, toda classe de indivíduos com certas características comuns mais específicas

O Novíssimo Aulete não apresenta nenhuma acepção com a rubrica referente ao domínio da Linguística. Ele apresenta, na acepção 5 (cinco), a definição de gênero morfológico/gramatical, mas a rubrica utilizada é Gram.(Gramática). Há referência aos gêneros literários na acepção 6 (seis), e aos gêneros abordados por Aristóteles na Retórica, na acepção 9 (nove), mas não há, nesse dicionário, a concepção de gênero de discurso, tal como se compreende atualmente, ou seja, como uma categoria que abrange textos dos mais diversos domínios, tanto literários quanto não-literários.

O Aurélio, por sua vez, apresenta, entre as diversas acepções da palavra gênero, a concepção de gênero morfológico, marcada com a rubrica E. Ling.: "Categoria gramatical (q.v) que dispõe os nomes de língua em classes (como feminino, masculino, neutro, animado e inanimado), de acordo com: (a) a referência pronominal (a casa/ela; o menino/ele); b) a concordância com os modificadores (a menina bonita/ o gato gordo); c) a presença de determinados afixos (como, p. ex. -triz)”.Além disso, o dicionário traz também, como fraseologismo, o termo gênero textual, definido como "produto (escrito ou falado) historicamente determinado, que constitui uma forma relativamente estável de enunciado”, em uma clara alusão à concepção de gêneros estabelecida por Bakhtin.

Percebe-se, portanto, no dicionário Aurélio, uma atenção à polissemia que o termo gênero apresenta nos Estudos Linguísticos, diferentemente dos dicionários Houaiss e Aulete. 


\section{CONSIDERAÇÕES FINAIS}

Diante das análises apresentadas, constatamos que os dicionários gerais apresentam alguns problemas quanto às definições de termos técnicocientíficos. Nos dicionários gerais, observou-se que, muitas vezes, desconsiderou-se a polissemia dos termos em análise no domínio da Linguística, mencionando-se apenas a sua realização como palavra e não como item terminológico.

Além disso, como já havia apontado Krieger (2011), em sua análise de minidicionários, falta sistematicidade na inclusão desses termos, visto que a inclusão desses itens é irregular. Há inclusão de alguns termos e exclusão de outros. Um exemplo é o caso da noção de gênero de discurso, assim como acepções do termo texto específicas da terminologia da Linguística, desconsideradas pelos dicionários Houaiss e Novíssimo Aulete. Tratase de conceitos importantes no domínio da Linguística e que, portanto, requeriam uma maior atenção dessas obras lexicográficas.

Tal análise mostra que os dicionários analisados carecem de maior sistematicidade na abordagem de termos técnico-científicos, de modo que esses instrumentos possam mostrar-se úteis tanto para estudiosos de Linguística quanto para o público em geral. 
Beatrice Nascimento Monteiro ( beatricenmonteiro@hotmail.com)

Professora Assistente na Universidade Estadual do Piauí (UESPI).

Ismael Paulo Cardoso Alves (ismael.cardosoalves@hotmail.com)

Mestre em Linguística pela Universidade Federal do Piauí (UFPI).

\section{Como citar esse artigo}

MONTEIRO, B, N; ALVES, I. P.C. Definições de termos técnico-científicos do domínio da Linguística em dicionários gerais. Revista Gatilho, UFJF, v. 19, p. 136-155. dez. 2020.

\section{Definitions of technical-scientific terms in the field of linguistics in general dictionaries}

ABSTRACT: Lexicography is an area that has expanded greatly in recent years. Inserted in the bias of analysis of lexicographic works, the article turns to a subset of the general lexicon: the more concrete terminological items, terms of the domain of Linguistics. Taking, as it works, generally aiming at the correction of essentials in the works, analyzing the systematics of the inclusion of such terms as an adequacy and detailing of the definitive texts. The discussion was held mainly in Biderman (2001),Krieger (2007) and (2011), Almeida (2011), Maciel (2011), among others. The testimonies were: Houaiss (electronic), Novíssimo Aulete and Aurélio. We have selected, for an analysis, five lexical items that support both observations and more specific to the domain of Linguistics. The items found were: language, speech, text, speech and gender. As a result, requirements rule often disregard a polysemy of lexical items, encompassing only word usage functions, without mentioning their specific use in linguistics.

KEYWORDS: Technical-scientific terms. General dictionary. Lexicography. 


\section{REFERÊNCIAS:}

ALMEIDA, Gladis Maria. Quais os critérios que deveriam orientar os lexicógrafos na inserção de termos e da fraseologia especializada em dicionários gerais? In: XATARA, Claudia; BEVILACQUA, Clesi Regina; HUMBLÉ, Philippe René (Orgs.). Dicionários na teoria e na prática: como e para quem são feitos. São Paulo: Parábola Editorial, 2011. Entrevista concedida aos organizadores da obra. p. 91-93.

ANDRADE, Maria Margarida de. Lexicografia, terminologia: definições, finalidades, conceitos operacionais. In: OLIVEIRA, Ana Maria; ISQUERDO, Aparecida Negri. As ciências do léxico: lexicologia, lexicografia, terminologia. Campo Grande, MS: Ed. UFMS, 2001. p. 191-200.

AUlETE, Caldas. Dicionário Contemporâneo da Língua Portuguesa. Rio de Janeiro: Lexikon, 2014. Versão digital. Disponível em: <https://www.aulete.com.br/>. Acesso em: 20/03/2018.

BARROS, Lídia. Quais aspectos diferenciam a elaboração de uma obra terminográfica de uma lexicográfica? In: XATARA, Claudia; BEVILACQUA, Clesi Regina; HUMBLÉ, Philippe René (Orgs.). Dicionários na teoria e na prática: como e para quem são feitos. São Paulo: Parábola Editorial, 2011. Entrevista concedida aos organizadores da obra. p. 143-145.

BIDERMAN, Maria Tereza. As ciências do léxico. In: OLIVEIRA, Ana Maria; ISQUERDO, Aparecida Negri. As ciências do léxico: lexicologia, lexicografia, terminologia. Campo Grande, MS: Ed. UFMS, 2001.p. 13-22.

FERREIRA, Aurélio Buarque de Holanda. Novo Dicionário Aurélio (Eletrônico). Versão 7.0. Curitiba: Positivo, 2010.

HOUAISS, Antônio. Dicionário Eletrônico Houaiss da Língua Portuguesa. Versão 3.0. São Paulo: Objetiva, 2009.

KRIEGER, Maria das Graças.Tipologias de dicionários: registros de léxico, princípios e tecnologias. Calidoscópio, São Leopoldo, v. 4, n. 3, pp. 141-147, set./dez. 2006.

- Termos técnico-científicos em minidicionários: problemas de inclusão e de definição. In: CARVALHO, Orlene Lúcia; BAGNO, Marcos. Dicionários escolares: políticas, formas e usos. São Paulo: Parábola Editorial, 2011.

MACIEL, Ana Maria. Quais aspectos diferenciam a elaboração de uma obra terminográfica de uma lexicográfica? In: XATARA, Claudia; BEVILACQUA, Clesi Regina; HUMBLÉ, Philippe René (Orgs.). Dicionários na teoria e na prática: como e para quem são feitos. São Paulo: Parábola Editorial, 2011. Entrevista concedida aos organizadores da obra. p. 145-147. 